\title{
The Paradox of Online Education: Images, Perceptions, and Interests
}

\author{
Ali Kamali, Ladan Kianmehr \\ Missouri Western State University, St. Joseph, M.O., USA
}

\begin{abstract}
Recent research findings point to a declining institutional interest in the necessity of online education. This study, therefore, proposes to examine a number of key pedagogical questions pertaining to the student images and perception about the relevance and usefulness of the e-environments to their study habits; their experiences and expectations; and the effects that the e-environment has on the decision to enroll in online classes. This paper further aims to add to the literature by providing useful information that can aid educators and administrators for enhancing the image and tendencies for a set of desired e-environments in higher education. A random sample of 473 students at a Midwestern liberal arts public university in the United States constituted the working sample in this study. Two additive scales-Structural Motives Scale and Experiential Factors Scale - measure the imagery and the reasons for the student preference for a learning environment-i.e., online, ground, or hybrid courses. Descriptive, bivariate, and regression analysis supported the model that explained the reasons for the popularity of online learning environment.
\end{abstract}

Keywords: online education, e-learning environment, e-sources, online imagery, information technology (IT) challenges

\section{Introduction}

Current higher education is a diverse environment with varied curricular contents, mixed student composition, and a wide range of opportunities in each institution. A question for the stakeholders in this environment pertains to the factors affecting the educational achievements of the students. This issue becomes particularly relevant given the current surge in incorporating information technology (IT) in teaching and learning, a movement that had been most notably supported by the stakeholders up to the last decade as a winning card for higher education institutions to remain afloat in a highly competitive market.

Incorporating IT in teaching and learning has evolved as a credible practice in higher education. Web-based educational platforms have grown steadily in the past years. Offering online classes has grown 25\%-38\% since 2002 (Allen \& Seaman, 2013); and the proportion of students taking online courses increased by $32 \%$. Recent scholarship does not dispute the credibility or effectiveness of electronic resources in the educational achievements of the students (Driscoll, Hunt, Tichavsky, \& Thompson, 2012; O'Neill, Singh, \& O'Donoghue, 2004). Likewise, we do not dispute IT's effectiveness, nor have we questioned the credibility of

Ali Kamali, Ph.D., distinguished professor and graduate faculty, Department of Economics, Political Science, and Sociology, Missouri Western State University.

Ladan Kianmeher, M.S., adjunct professor, Department of Computer Sciences, Mathematics, and Physics, Missouri Western State University. 
online vs. ground courses. But a recent study by Babson Survey Research Group (Allen \& Seaman, 2014) indicated a decline in institutional perceptions about the necessity of online education, and the rising number of those who remained neutral on the topic.

These latter findings are alarming. They have stimulated our curiosity about the popularity of IT as an effective, or even necessary, tool in contemporary educational environments. Our concerns led us to be suspicions of the images and perceptions that students have developed about IT in relation to their experiences, motivation and cognitive development, resource utilization, preparation, and academic success which inevitably affect their decision to enroll in e-classes. Hence, we asked whether there is a parallel between the decline in institutional perceptions and the imageries among the students.

Given the above, we propose to examine a number of key pedagogical questions pertaining to the student images and perception about the relevance and usefulness of e-environments to their experiences with and expectations of this learning environment; and the effects that their experiences have on their decision whether to enroll in an e-class. Our intention is to add to the literature by providing useful information that can aid educators and administrators for enhancing the image and tendencies for a set of desired e-environments in higher education.

\section{Literature Review}

The literature is saturated with the studies that have compared e-learning with ground courses. Many also focused on the end-users' perceptions about online courses. Most studies have found no compelling evidence on behalf of one learning environment over the other (York, 2008). These findings are not surprising, given the ubiquitous penetration of IT in education and the use of electronic devices in all walks of life.

For a while, we have assumed that electronic devices and other related resources (i.e., e-resources) help learning and educational achievements, but some (e.g., Paddock, 2013; Suarez-Brown, Grice, Turner, \& Hankins, 2012) have found quite the opposite. These latter findings are alarming; they warrant an exploration of the reasons for such a change of heart by administrators given that today's college students are characteristically a group of connected individuals through cell phones, e-mail, FaceBook, Twitter, etc.; their familiarity and use of multi-media technology, and the fact that the youth are the pioneers in learning and adopting technology, one would assume, complement their educational achievements. However, Junco (2012) suggested that one of the reasons for the failure of e-sources to deliver its promises in education is the time consumed on these devices or domains (instead of paying more attention to the schoolwork). This may be true, but one needs to take a closer look to see if these domains are used for completing homework assignments, exam preparation, and researching for other school related requirements, or whether students are using these devices predominantly for non-school related activities.

Granted that much time is spent on electronic gadgets, but such accusatory remarks dismiss the importance of the mechanical structure of the learning environment and the quality of the contents that could affect students' success. It is a given that educational institutions have adopted the business model (i.e., a form of consumerism); therefore, they should focus on the provider (i.e., stakeholders) and his/her habits. That is, we need to focus on the clarity of the course design and structure, contents quality, and the promotion of critical thinking must be noted in an e-environment as important factors leading to effective pedagogical practices (Garrison \& Anderson, 2003; Suarez-Brown et al., 2012) instead of blaming the students. This is evident in the literature. For example, Driscoll et al. (2012) recognized open and timely student-instructor and student-student 
communications as an important structural factor in a successful e-environment; Boettcher (2011) pointed out that an effective learning environment requires available resources; Sanders and Lafferty (2010) focused on the importance of the learning platforms and ease of navigation; and the results of a study by the Center for Teaching Learning at the University of Maryland University College (2013) showed the importance of a supportive learning community.

Furthermore, the literature suggests that learning in either environment - electronic, ground, or hybrid - is positively correlated with the student's technical (computer) skills, availability and accessibility of the e-sources, and the absence of other socio-cultural and economic challenges. Educators must be aware that functionality in an e-environment is dependent on the extent of a student's ability for self-regulation and independent learning, and that not all students learn in similar fashion or pace. Educators must ask themselves whether the e-environment is capable of providing equally valuable learning experiences for all students, and grant that the available interface provides alternative teaching modules in relation to different learning styles. In other words, the literature is suggesting that learning in an e-environment must be customized so that learning can fit the learner's capabilities.

Although customizing learning in the e-environment suggests a structural approach to learning-i.e., the emphasis on skills, system readiness, and platform — ignoring the content quality may render ineffective when learning outcomes are concerned. Alternatively, progressive research on pedagogy is aware of the symbiotic relationship between the curricular "contents" and the environmental "structure" in which learning takes place. One point that is worth emphasizing is that technology should not be treated as the magic wand to dictate learning (Kamali, 2013).

It should further be noted that learning is an accumulation of all of the activities with which a student is engaged throughout his/her educational career. Aside from using the e-sources for completing exams and assignment, students develop other experiences through cooperative learning (Hassanien, 2007). The question is, how valuable is this type of experiences from the point of view of a student? Pauli, Mohiyeddini, Bray, Michie, and Street (2008) have suggested that the literature is silent on the student perceptions about such experiences. If learning encompasses latent functions such as developing skills for teamwork, leadership, problem-solving, and other qualities beyond the intended curricular contents, then it can be confidently stated that the student experiences with the e-environment are key factors in the learning process. Because there is no face-to-face interaction in the e-environment, and since e-mail contacts may not be responded to in a timely fashion, group work may become counterproductive. The problem is exacerbated if there is no structure for students' engagement in applied learning.

In general, literature suggests that the student perception of the method of course delivery (online vs. ground) is a function of open, one-on-one - preferably, face-to-face - communication; and that quality teaching and learning environment is equally important in either online or ground courses (Hill, Lomas, \& MacGregor, 2003). However, quality is also assessed in terms of compliance with the course requirements (Stross, 2011).

In summary, the current scholarship on learning points to the provision of a comprehensible learning environment, utilizing e-sources suggests the importance of creating a student-oriented learning environment. Although pedagogical designs are becoming more elaborate, their necessity and/or effectiveness is being questioned. It is clear that many have invested a great deal of time and energy, as well as human and social capital, in higher education to justify the inclusion of IT in education. But the above review shows that the issues are diverse; the findings are contradictory and ambivalent; and although the interest in incorporating IT 
in education is still growing, the institutional perceptions about the necessity of online education is gradually becoming neutral or negative. These perceptions are those of the institutional stakeholders (board members, administrators, and members of the faculty); they do not necessarily reflect those of the students - hence, the necessity of exploring this issue from the views expressed by the students.

\section{Theoretical Framework}

The Babson Survey Research Group's (Allen \& Seaman, 2014) finding about the top administrators' perceptual decline about the necessity of online education is alarming. However, a 2013 report by Re:fuel, a market research company (Boklan, 2013), showed that the student interest in taking online courses doubled (from $23 \%$ to $45 \%$ ) since 2008 . This is paradoxical: whereas administrators are gradually losing interest in the necessity of online education, the number of students interested in taking online classes has risen.

In this study, we decided to explore the reasons for the popularity of online education among the students, and focused our attention on the correlates that relate to the challenges associated with this learning e-environment, the student experiences with online education, and the images that this environment has created for the students. We have not dismissed the importance of the course structure and contents in attracting students to a given teaching and learning module; however, we treated them as factors that affect one's experience and the resulting perception about online education.

Since our intention is to explore the reasons for the popularity of online education among students, we have predicted two sets of correlates relating to the tendency or preference to enroll in online classes. We envisioned that this tendency may be affected by one's perceptions of the value of the e-environment, which itself is influenced by a host of other structural and experiential factors. Hence, we hypothesized:

H1: Structural factors, such as family circumstances, work schedule, learning style (e.g., audio, visual, etc.), self-reliance in meeting the deadlines, and other preoccupations are elemental factors (or reasons) affecting the student preferences for, and the actual enrollment in, online classes.

H2: The value placed on online education (courses or degrees) and the experience (or practical knowledge) with that learning environment influence a learner's preferences for a learning environment (i.e., online, ground, or hybrid classes) and the actual enrollment.

We further broke down Hypothesis 2 into the following five sub-hypotheses:

H2.1: Students' preference for a learning environment is dependent on their experiences with that environment.

H2.2: Students' experiences with a learning environment affect their perception of the value (imagery) of that they attribute to that learning environment.

H2.3: The actual enrollment in a particular learning environment is correlated with the preference that a student has for that environment.

H2.4: The value associated with a learning environment (imagery) is a precursor for enrolling in that learning environment.

H2.5: A student's preference for a particular learning environment is affected by the value (imagery) that he/she places on that learning environment.

H3: The preference for a learning environment (i.e., online, ground, or hybrid courses), the value associated with one learning environment, and the actual enrollment in that learning environment depend on the student perceptions of the challenges that the learning environment poses.

Hypothesis 3 can be broken down to the following: 
H3.1: The value placed on a learning environment is dependent on the challenges posed by that learning environment.

H3.2: One's preference for a learning environment depends on his/her perception of the challenges associated with that environment.

The subsets of Hypothesis 3 also include the relevance of preference for a learning environment and the imagery associated with that environment in enrollment decision, which is included among the Hypothesis 2 subsets (H2.5). In addition, we propose that:

H4: A student's experience with the online learning environment directly affects his/her decision to enrolling in online classes.

H5: The perceived challenges posed by the online learning environment affect a student's decision to enrolling in online classes.

Collectively, the above framework assumes that an attractive e-learning environment is justified according to the learners' expectation of the course, the logistic set-up of the courses, and the students' sense of accomplishment (see Figure 1).

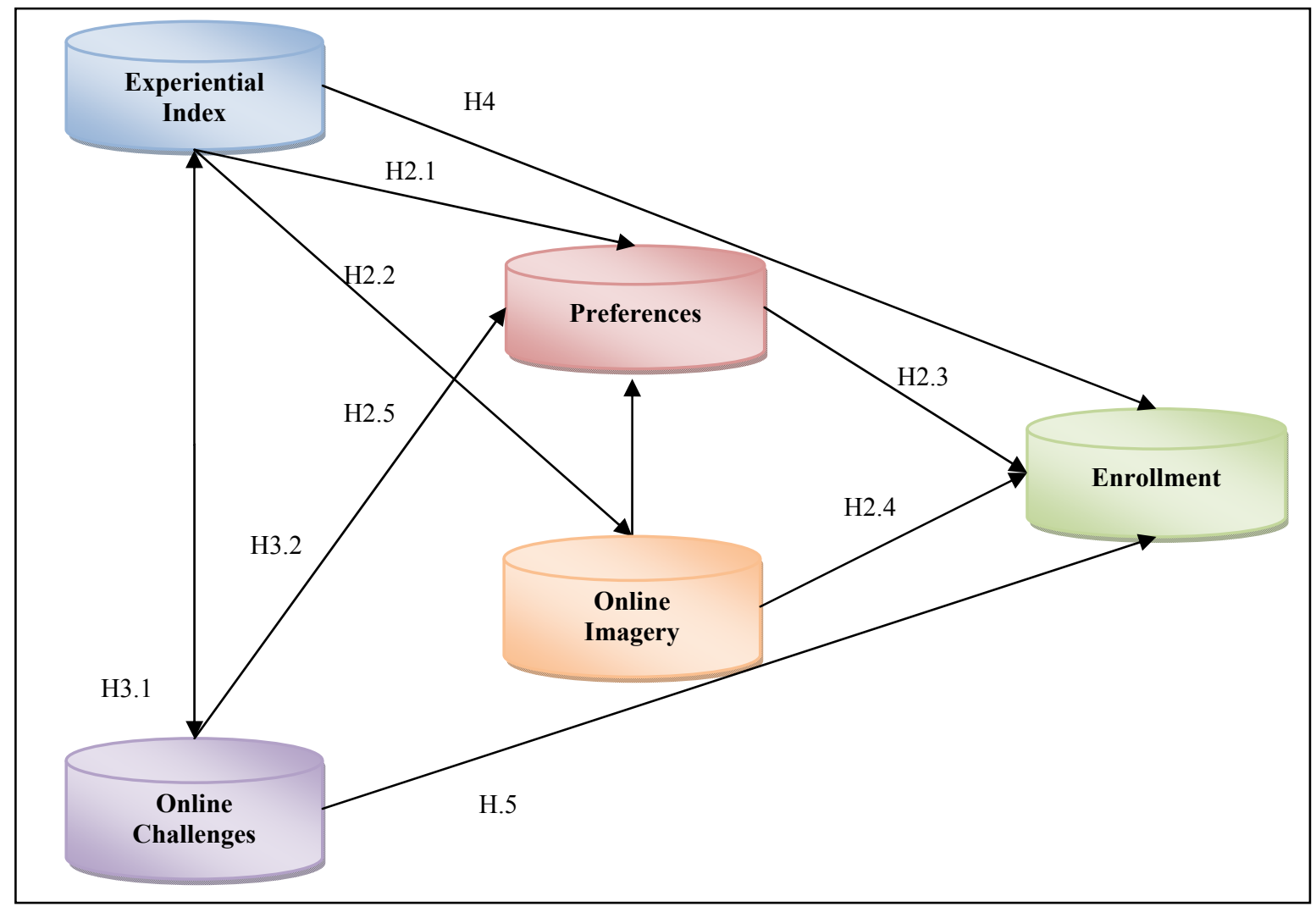

Figure 1. Theoretical path model.

\section{Methodology}

Although the nature of the above hypotheses and the proposed theoretical model suggest syllogism, the scatter plot we created suggested linearity among the variables in this study (Mertler \& Vannetta, 2002). While our main intention in this study is to find factors that affect a student's preference for a learning environment, we also aimed at determining the subsets of variables that correlated most with the actual enrollment in e-classes. 


\section{Sample and Data}

A survey of 625 students at a Midwestern liberal arts public university (approximately 6,000 student population) generated the data for this study. Monday classes that met at 10:00 a.m. were randomly selected in order to avoid duplicating respondents. We employed self-administered questionnaire as our method of data collection. After cleaning the outliers, the working sample became approximately $10 \%$ of the working population (473), which is adequate enough to ensure reliability (Monette, Sullivan, \& DeJong, 2010; Neuman, 2011). We also piloted the questionnaire for simplifying, rephrasing, or eliminating problematic items in order to increase content validity and reliability.

Close to $58 \%$ of the sample were females, and $42 \%$ were males. The sample is comprised of $85 \%$ traditional students - typically 18-24 years of age, who entered the university with no delay from high school, may work part-time, is financially dependent on other sources (Deil-Amen, 2011). Approximately $72 \%$ of the participants were employed, of whom only $11.2 \%$ were employed full-time; $62 \%$ live off campus; and $52 \%$ have taken at least one online class, but all have had classes that incorporated some sort of e-sources.

\section{Variables and Measures}

The questionnaire included only quantitative measures that assessed the images and challenges that IT poses in the e-learning environment, as well as questions that measured a collection of structural factors and their relevance to online education. We also focused on the student academic experiences with the e-environment and their preferences for one learning module vis-à-vis the other. The instrument also assessed the reasons for the student preferences, and their perceptions regarding the usefulness of electronic sources and technology in learning and academic achievement.

Because of the ordinal nature of the variables, two additive scales, Structural Motives Scale and Experiential Factors Scale, were developed as constructs measuring the reasons for the student preference for a learning environment-i.e., online, ground, or hybrid courses. Structural Motives Scale entailed items such as family circumstances, work schedule, learning style (e.g., audio, visual, etc.), self-reliance in meeting the deadlines, and other preoccupations. The Experiential Factors Scale measured the student experiences with online education and e-sources. Variables in this scale reflected perceptions regarding the previously taken online classes, the frequency of utilizing e-sources, and the view on the overall effectiveness of online classes and usefulness of e-sources.

We also constructed two additional scales: Online Challenges Scale, which measured academic or logistic issues that may arise in an online environment. This scale entailed having reliable Internet connection, the ability to maintain fluid interaction with the course instructor and fellow classmates, receiving timely assistance and feedback from the instructor, note-taking, meeting deadlines, and ease of forming study groups or teams for team projects, Our last scale, Online Imagery Scale, measured the student perception of the value of online education (classes and/or degrees). All variables were originally measured according to a 5-point Likert scale, which were eventually recoded into three hierarchical categories indicating agreement (high), neutral (medium), or disagreement (low) with the items of the scale.

We cross-checked the items in each scale by using Cronbach's $\alpha$ as the reliability test. The value of $\alpha$ for Online Challenges Scale was 0.86 (which is above the recommended 0.70). Cronbach's $\alpha$ for Online Imagery Scale and Experiential Factors Scale were 0.60 and 0.61 , respectively. Since these values are below the recommended level, we ran a test of internal consistency for the validity of the instrument. The bivariate 
Spearman's Rho value for pairs of items in this scale rendered statistically significant at $p \leq 0.001$.

\section{Analysis and Findings}

The preliminary descriptive statistics indicate that only $51.8 \%$ of the students have taken at least one online class, but $68.5 \%$ of the respondents expressed preferring ground (on-campus) courses. With the advent of technology and the increasing number of online course offerings, we had expected a greater number of students who would be eager to enroll in online classes. However, this finding seems compatible with our original suspicion about the contradiction between students and administrators. Thus, we further explored the reasons for this shift. One anomaly we found was the shift in the popularity of online education among students: $76.7 \%$ did not perceive the e-environment as more effective than the traditional settings; almost one half (46.6\%) expressed low opinion of the value associated with online classes and online degrees; although a smaller proportion (36.1\%) felt that online classes are more challenging than the traditional classroom settings, a majority of $49.3 \%$ did not differentiate between the two.

Although some respondents expressed negative views about online courses, the interest in online education is high. We became curious about this contradiction. The students' answers to a set of multiple response questions about the most important reasons for taking online courses revealed work schedule to be the single most important reason for a large number of respondents $(50.2 \%)$, followed by the perception that online classes are equipped with audio-visual tools (28.7\%). Students who favored e-classes because of the audio-visual appeal did so because they find this method of delivery more compatible with their learning style. Other factors that seemed elemental in enrolling in e-classes were the students' perception of their computer skills and the distance they travel to the campus (21\% respectively). We also found that a major challenge of online classes to be forgetfulness or missing deadlines: only $24 \%$ of the students in our survey never missed any deadlines in an e-class.

However, when cross-checked for sex and student status (tradition and nontraditional), we noticed several anomalies that contradict the male-female or traditional-nontraditional stereotypes in relation to the popularity of online education or using e-sources (see Table 1). For example, according to the data in Table 1, the structural reasons for selecting online classes are disproportionately stronger among the traditional students when compared with the nontraditional students. However, the structural tendencies (reasons) for enrolling in e-classes are stronger among the traditional female students when compared with their male counterparts. This finding is surprising because popular assumptions often associate men with computers and IT. The preference toward online education among the nontraditional female students was found to be due to their preoccupation with work and family. When sex and student status were controlled for employment status, preoccupation with work and family appeared to be a strong reason among full-time employed nontraditional male and female students for preferring online education (three times as many compared to their traditional counterparts). This justifies the contradiction we see in Table 1. Hence, the empirical data supported Hypothesis 1.

We further explored the reasons for a student's preference for online education by looking at the bivariate correlation between pairs of variables in our theoretical model (see Table 2). Our analysis indicates a statistically significant correlation between eight out of nine pairs in the correlation matrix: experiential factors and preference to enroll in online classes $(r=0.60 ; p<0.001)$, experiential factors and online imagery $(r=0.35 ; p<0.001)$, experiential factors and the actual enrollment in an online class $(r=0.19 ; p<0.001)$, preference for online environment and enrollment in online classes $(r=0.25 ; p<0.001)$, and the effects that 
online imagery has on one's preference for the online environment $(r=0.33 ; p<0.001)$. However, the actual enrollment in online classes did not show any significant correlation with online imagery $(r=0.02 ; p=0.70)$. In general, the empirical data supported all sub-sets of Hypothesis 2, except Hypothesis 2.4. Hence, the empirical data supported the importance of the structural factors, but the value associated with a learning environment (imagery) did not appear to be a precursor for enrolling in that learning environment.

Table 1

Factors Affecting the Decision for Taking Online Classes Controlled for Sex and Student Status

\begin{tabular}{|c|c|c|c|c|}
\hline \multirow{2}{*}{ Structural factors } & \multicolumn{2}{|c|}{ Male } & \multicolumn{2}{|c|}{ Female } \\
\hline & Traditional & Nontraditional & Traditional & Nontraditional \\
\hline Family circumstances & $73.1 \%$ & $26.9 \%$ & $60.9 \%$ & $39.1 \%$ \\
\hline Work schedule & $84.1 \%$ & $15.9 \%$ & $86.5 \%$ & $13.5 \%$ \\
\hline Computer skills confidence & $80.0 \%$ & $20.0 \%$ & $89.1 \%$ & $10.9 \%$ \\
\hline Learning style & $82.5 \%$ & $17.5 \%$ & $89.7 \%$ & $10.3 \%$ \\
\hline Travel to campus & $82.9 \%$ & $17.1 \%$ & $83.9 \%$ & $16.1 \%$ \\
\hline Regrets (taking ground courses) & $77.8 \%$ & $22.2 \%$ & $99.9 \%$ & $00.1 \%$ \\
\hline Extracurricular activities & $93.6 \%$ & $6.4 \%$ & $95.5 \%$ & $4.5 \%$ \\
\hline Fear of Procrastination & $97.1 \%$ & $2.9 \%$ & $84.2 \%$ & $15.8 \%$ \\
\hline
\end{tabular}

Table 2

Descriptive Statistics and Bivariate Correlation Values Among Constructs of E-Learning

\begin{tabular}{|c|c|c|c|c|c|c|c|c|c|c|}
\hline Variables & Mean & $S D$ & 1 & 2 & 3 & 4 & 5 & 6 & 7 & 8 \\
\hline 1. Sex & 1.39 & 0.61 & - & -0.04 & 0.08 & 0.07 & 0.08 & -0.06 & -0.02 & 0.03 \\
\hline 2. Student status & 1.12 & 0.36 & - & - & -0.05 & $0.10^{*}$ & 0.01 & 0.03 & -0.08 & -0.03 \\
\hline 3. Employment status & 1.83 & 0.60 & - & - & - & $0.16^{* *}$ & 0.01 & 0.04 & -0.02 & -0.02 \\
\hline 4. Enrollment & 1.60 & 0.64 & - & - & - & - & $0.25^{* *}$ & $0.19^{* *}$ & 0.02 & $-0.64^{* *}$ \\
\hline 5. Preferred setting & 1.25 & 0.49 & - & - & - & - & - & $0.60^{* *}$ & $0.33^{* *}$ & $-0.60^{* *}$ \\
\hline 6. Experiential factors & 1.27 & 0.52 & - & - & - & - & - & - & $0.35^{* *}$ & $-0.23^{* *}$ \\
\hline 7. Online imagery & 1.68 & 0.72 & - & - & - & - & - & - & - & $-0.12^{*}$ \\
\hline 8. Online challenges & 2.21 & 0.68 & - & - & - & - & - & - & - & - \\
\hline
\end{tabular}

Notes. ${ }^{* *}$ Correlation is significant at $p<0.001$ level (2-tailed); ${ }^{*}$ Correlation is significant at $p \leq 0.05$ level (2-tailed).

Further bivariate correlation analysis tested the relationship between challenges posed by the e-environment and preference given to the e-environment, online imagery, and the actual enrollment in online classes. The bivariate test statistics showed a strong and statistically significant correlation between challenges posed by the e-environment and preference given to the e-environment $(r=-0.60 ; p>0.05)$ : those who perceive the e-environment more challenging than the traditional lecture classes prefer ground courses. This finding contradicted Hypothesis 3.2. The Online Challenges Scale showed a strong and statistically significant negative correlation with the actual enrollment in e-classes $(r=-0.64 ; p<0.001)$ : obstacles and challenges associated with the e-environment seem to deter a typical student from taking online classes; the more challenging the e-environment, the less likely he/she will enroll in online classes. Although the correlation between online challenges and online imagery is statistically significant, it is fairly weak $(r=-0.12 ; p=0.04)$. It is less likely for a student to have a positive impression of a highly challenging online course. Overall, the data supported Hypothesis 3 and its subsets that the student perception of the challenges posed by a learning environment (i.e., online, ground, or hybrid courses) affects his/her preference for that learning environment, the value (imagery) 
that one associates with that learning environment, and the actual enrollment in that type of classes.

Additional bivariate analyses that tested the correlation between experiential factors and enrollment verified Hypothesis $4(r=0.19 ; p<0.001)$. Therefore, enrolling in an online learning environment is directly affected by one's experience (experiential factors) with this learning environment. Hence, the data supported Hypotheses 4 and 5.

In summary, the above tests statistics support the overall model proposed in this study. Although the bivariate coefficients ( 8 out of 9 ) showed statistically significant correlations between the respective pairs of constructs in this study, the linear presentation was unable to verify the hierarchical order of the mode and validate the constructs most influential in predicting the decision to enroll in e-classes. Therefore, we conducted a stepwise multiple regression analysis as the third layer of analysis in order to ensure consistence between the proposed model and the empirical data; and, if the mode is consistent, which variables have the highest direct effect on the decision to enroll in e-classes. In doing so, we also conducted several other tests that aided us in deciding the relevance of our data to the theoretical model in this study. For example, tests of collinearity indicated that the tolerance statistics were all greater than 0.1 (Mertler \& Vannetta, 2002), which ensured $>0.98$ tolerance level for all constructs. Accordingly, we confirm that the variables are independent of each other.

Regression statistics show that the model tested in this study is significant $\left(F_{(4,312)}=57.16 ; p<0.001\right)$. The model accounts for $42.3 \%$ of variance in the decision to enroll in e-classes $\left(R^{2}=0.423\right)$. Therefore, the model is a good predictor of the effects that preference for a learning environment $(\beta=0.18 ; p=0.002)$, online imagery $(\beta=-0.11 ; p=0.03)$, and online challenges $(\beta=0.60 ; p<0.001)$ have on a student's enrollment decision. However, the empirical data showed a weak and statistically not significant effect by the scale that measured a student's experience with the e-environment $(\beta=-0.01 ; p=0.74)$. According to the regression model, a student's experiences with prior online classes do not affect his/her decisions for future enrollment in such classes. In addition, when tested for the $t$ scores for these constructs, all test statistics were greater than 1.96 ( $t=3.80$ for preference, $t=-2.25$ for online imagery, and $t=-13.10$ for online challenges), except for $t=-0.34$ for experiential factors. The small $t$ score for experiential factors indicates the spurious nature of the effects that one's experience with the e-environment may have on the actual enrollment on online classes. Conversely, tests statistics for other constructs indicated that their confidence intervals are, therefore, greater than $95 \%$. A summary of the regression data is presented in Table 3.

Table 3

Regression Coefficients for the e-Environment Measurements ${ }^{a}$

\begin{tabular}{|c|c|c|c|c|c|}
\hline Constructs & $B$ & $S E$ & $\beta$ & $t$ & Sig. \\
\hline (Constant) & 2.918 & 0.146 & - & 19.947 & $<0.001$ \\
\hline Preference & 0.173 & 0.056 & 0.178 & 3.083 & 0.002 \\
\hline Experiential factors & -0.023 & 0.067 & -0.019 & -0.338 & 0.736 \\
\hline Online imagery & -0.090 & 0.040 & -0.104 & -2.249 & 0.025 \\
\hline Online challenges & -0.562 & 0.043 & -0.595 & -13.092 & $<0.001$ \\
\hline \multicolumn{6}{|c|}{$R=0.65, R^{2}=0.423$, adjusted $R^{2}=0.416, F_{(4,312)}=57.161$, Sig. $\leq 0.001$} \\
\hline
\end{tabular}

Notes. ${ }^{a}$ Dependent variable $=$ Enrollment in e-classes. Selecting only cases when at least one e-class is taken.

\section{Discussions and Conclusions}

Studies of the relevance of IT to education help us understand the urgency and importance of the institutional 
commitments to the students' needs if higher education institutions are consciously implementing the business approach to education. While contradicting many commonsense assumptions, the findings in this study verified that students' experience with online classes and online education (experiential factors and online challenges) are not necessarily pull or push factors for deciding to enroll in e-classes; other structural factors seemed more relevance in such decisions. In addition to the statistically significant independent bivariate correlations that attested to the validity of the hypotheses in this study, further tests that looked into the hierarchical order of the constructs also indicated a larger degree of variance (42\%) in decisions to enroll in e-classes to be accounted for by the independent predictors tested in this study. Thus, the findings in this study question the accuracy of assuming a declining enrollment in online education because of the negative student experiences with online education. We also question the relevance of obstacles and challenges associated with the e-learning environment as deterring factors from enrolling in online classes. Nonetheless, we would extrapolate from our findings that positive experiences with the system quality may reduce frustration and, therefore, enhance online imagery (an area that needs to be explored further).

In addition, despite the findings in this study, we suggest that closer attention must be paid to the structural stability of a course if presented online. Our study verified that a high volume of interaction with the course instructor and classmates significantly affects the perceptions about the validity of a course, but the value placed on an e-class, or an online degree, is another issue all together. Our findings with regard to maintaining an effective engagement with the course, the instructor, and classmates are compatible with the literature, but it is not clear whether such interactions or the value associated with a course quality is a measure of the student's acceptance of online education. Nonetheless, we recommend greater user interface for increasing the value associated with a course.

We have noticed in our review of the literature that students often neglect the course deadlines and procrastinate. Forgetfulness and negligence are also issues expressed by those participated in our study. This is a deterrent to a successful completion of the course. However, we did not observe a consistent pattern suggesting whether a group of students are more prone to such behaviors vis-à-vis others. One of the biggest issues in regards to missing deadlines, or forgetfulness, is that many are under the delusion that e-classes must be more flexible. We recommend that e-instructors develop firm strategies for maintaining the course deadlines. Perhaps, further research in this area may shed more light on this issue.

Finally, our research reiterated the importance of the challenges that online education (i.e., the e-environment) can pose on the students. We have noticed that most students in our study are aware of the challenges associated with online education, but are also attracted to such a challenging learning environment. This is contrary to the commonsense that most people avoid challenging courses. As we have indicated in our analysis of the results, enrollment in online classes may be a necessity for many students since their attraction, or willingness, to enroll in e-classes stem from other structural factors. This, however, does not dismiss the quality of the course contents as a deciding factor, given that more challenging courses are also content driven (Lin, Tseng, Weng, \& Su, 2009). Hence, we suggest enhancing content quality of online education (the curriculum) will increase student enrollments in such an environment.

\section{References}

Allen, E., \& Seaman, J. (2013). Changing course: Ten years of tracking online education in the United States. Bacon Survey Research Group. Retrieved: May 2015, from http://www.onlinelearningsurvey.com/highered.html 
Allen, E., \& Seaman, J. (2014). Grade change: Tracking online education in the United States Bacon Survey Research Group. Retrieved May 2015, from http://www.onlinelearningsurvey.com/reports/gradechange.pdf

Boettcher, J. (2011). Ten best practices for teaching online: Quick guide for new online faculty. Retrieved February 2015, from

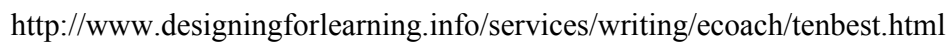

Boklan, J. (2013). Students taking online courses jumps 96 percent over 5 years. Retrieved May 2015, from http://campustechnology.com/articles/2013/06/24/report-students-taking-online-courses-jumps-96-percent-over-5-years.aspx

Deil-Amen, R. (2011). The "traditional" college student: A smaller and smaller minority and its implications for diversity and access institutions University of Arizona, Center for the Study of Higher Education (Paper prepared for The Mapping Broad Access Higher Education Conference, Stanford University).

Driscoll, J. K., Hunt, A., Tichavsky, L., \& Thompson, G. (2012). Can online courses deliver in-class results? A comparison of student performance and satisfaction in an online versus face-to-face introductory sociology course. Teaching Sociology, 40(4), 312-331.

Garrison, D., \& Anderson, T. (2003). E-learning in the 21st century: A framework for research and practice. London, U.K.: Routledge/Falmer.

Hassanien, A. (2007). A qualitative student evaluation of group learning in higher education. Higher Education in Europe, 32(2/3), 135-150.

Hill, Y., Lomas, L., \& MacGregor, J. (2003). Students' perception of quality in higher education. Quality Assurance in Higher Education, 11(1), 15-20.

Junco, R. (2012). The relationship between frequency of FaceBook use, participation in FaceBook activities, and student engagement. Computers \& Education, 58(1), 162-171.

Kamali, A. (2013). Antecedents of adopting e-learning: Toward a model of academic e-learning acceptance. Information System Education Journal, 11(2), 4-14.

Lin, H. Y., Tseng, S., Weng, J., \& Su, J. (2009). Design and implementation of an object oriented learning activity system. Educational Technology \& Society, 12(3), 248-265.

Mertler, C., \& Vannetta, R. (2002). Advanced and multivariate statistical methods: Practical application and interpretation (2nd ed.). Los Angeles, C.A.: Pyrczak Publishing.

Monette, D., Sullivan, T., \& DeJong, C. (2010). Applied social research: Tools for the human services (9th ed.). New York, N.Y.: Thompson.

Neuman, L. (2011). Social research methods: Qualitative and quantitative approaches (7th ed.). New York, N.Y.: Pearson Publishers.

O’Neill, K., Singh, G., \& O’Donoghue, J. (2004). Implementing e-learning programs for higher education: A review of the literature. Journal of Information Technology Education, 3, 314-323.

Paddock, C. (2013, December 9). Cell phone use linked to lower course grades, anxiety. Medical News Today. Retrieved from http://www.medicalnewstoday.com/articles/269882

Pauli, R., Mohiyeddini, C., Bray, D., Michie, F., \& Street, B. (2008). Individual differences in negative group work experiences in collaborative student learning. Educational Psychology, 28(1), 47-58.

Sanders, J., \& Lafferty, N. (2010). Twelve tips on usability testing to develop effective e-learning in medical education. Medical Teacher, 32, 956-960.

Stross, R. (2011). In breaking down walls, does online education sacrifice quality? Open Education. Retrieved February 2015, from http://www.openeducation.net/2011/02/10/in-breaking-down-walls-does-online-education-sacrifice-quality

Suarez-Brown, T., Grice, H., Turner, T., \& Hankins, J. (2012). The challenges of delivering quality online and distance education courses. Review of Business Research, 12(5), 94-104.

University of Maryland University College, Center for Teaching and Learning. (2013). Best practices for online teaching. Retrieved February 2015, from http://www.umuc.edu/ctl/upload/bestpractices.pdf

York, R. (2008). Comparing three modes of instructions in a graduate social work program. Journal of Social Work Education, 44(2), 157-171. 